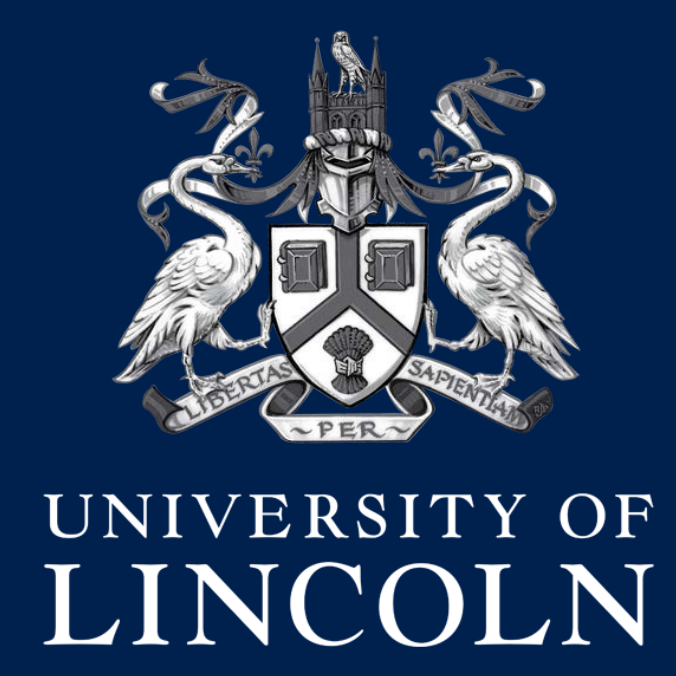

\title{
What do users value about the emergency ambulance service?
}

Fiona Togher ${ }^{1}$, Viet-Hai Phung ${ }^{1}$, Janette Turner ${ }^{2}$, Professor A. Niroshan Siriwardena ${ }^{1}$, Professor Alicia O'Cathain'

${ }^{1}$ University of Lincoln, ${ }^{2}$ University of Sheffield

Fiona Togher / Lincoln School of Health and Social Care / $5^{\text {th }}$ March 2013 


\section{Background}

- Narrow focus of current quality indicators for ambulance services.

- Patient perspective of care becoming increasingly important. 


\section{Aim}

- To investigate patients' experiences of the 999 ambulance service to understand the processes and outcomes important to them. 


\section{Method}

- Purposive sampling

- Three levels of response

- Category 1 = hear and treat

- Category 2 = see and treat

- Category 3 = see and convey 


\section{Method}

- Semi-structured interviews.

- Topic guide.

- NVivo8.

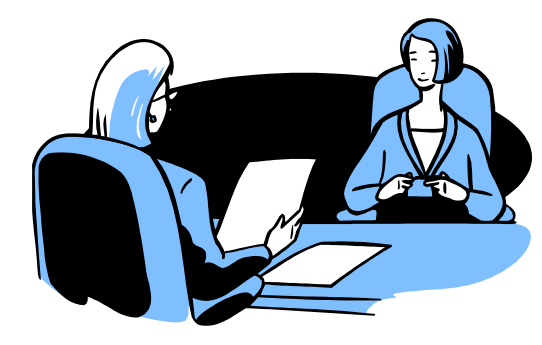

- Thematic analysis.

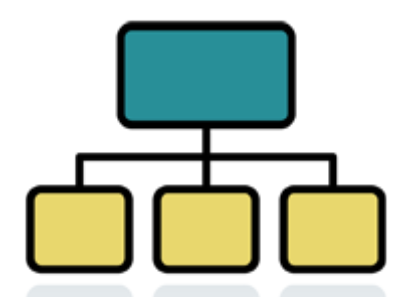




\section{Results}

11 Males and 11

Females participated

$(n=22)$

13 of the participants

were aged $65+$ over

\begin{tabular}{|l|l|l|l|}
\hline & $\begin{array}{l}\text { Hear and } \\
\text { treat }\end{array}$ & $\begin{array}{l}\text { See and } \\
\text { treat }\end{array}$ & $\begin{array}{l}\text { See and } \\
\text { convey }\end{array}$ \\
\hline $\begin{array}{l}\text { Official } \\
\text { Response } \\
\text { Category }\end{array}$ & 6 & 9 & 7 \\
\hline $\begin{array}{l}\text { Patient } \\
\text { Reported } \\
\text { Response } \\
\text { category }\end{array}$ & 2 & 7 & 13 \\
\hline
\end{tabular}




\section{Emerging themes}

\begin{tabular}{|c|c|}
\hline Theme & Sub-theme \\
\hline Not waiting too long for help & $\begin{array}{l}\text { - } \text { Alleviation of fear, distress and panic } \\
\text { - } \quad \text { Perceived need } \\
\text { - } \quad \text { Timeliness vs. time }\end{array}$ \\
\hline Information provision & - Communication style \\
\hline Professional relationship & $\begin{array}{ll}\text { - } & \text { Reassurance } \\
\text { - } & \text { Confidence in cliniciansabilities } \\
\text { - } & \text { Clinician behaviour and conduct }\end{array}$ \\
\hline $\begin{array}{l}\text { Smooth transition along the } \\
\text { prehospital care pathway }\end{array}$ & $\begin{array}{l}\text { - Call handling stage } \\
\text { - Wait for ambulance } \\
\text { - Time on scene } \\
\text { - Journey to hospital } \\
\text { - Handover }\end{array}$ \\
\hline
\end{tabular}




\section{Not waiting too long for help}

- The meaning of help was different for different people

- Distinction between needing and wanting a quick response time 


\section{Not waiting too long for help}

- Desire to have immediate contact with individual(s) that are perceived to know what they are doing 


\section{Information Provision}

- Patients wanted to be kept 'in the loop' with approximate response times

- The approach used to request information or disseminate it to patients was important

- Jovial vs. Formal 


\section{Professional Relationship}

- Patients valued the reassurance provided to them within the rapport developed with the clinicians

- There was an association between the reassurance provided and the confidence felt in the clinicians abilities to treat patients effectively 


\section{Smooth transition along the prehospital care pathway}

- Some patients reported the call handling stage as being the most highly valued stage

- Often the call handler would remain on the phone until the clinicians arrived 


\section{Smooth transition along the prehospital care pathway}

- Patients were satisfied with the assessments and treatment they received on scene

- Only voiced concerns if they were:

- not able to choose the hospital they were being admitted to

- the hospital care was not at the same high standard as the prehospital service 


\section{What have we learnt?}

- Aspects of prehospital emergency care other than 'response time' were highly valued by patients

- It was challenging to engage participants in considering factors other than response times for potential new outcome measures 


\section{Where do we go from here?}

- Results will contribute to the identification of candidates for new outcome measures

- Potential implications for the delivery of urgent and emergency primary care services - clinical education? 


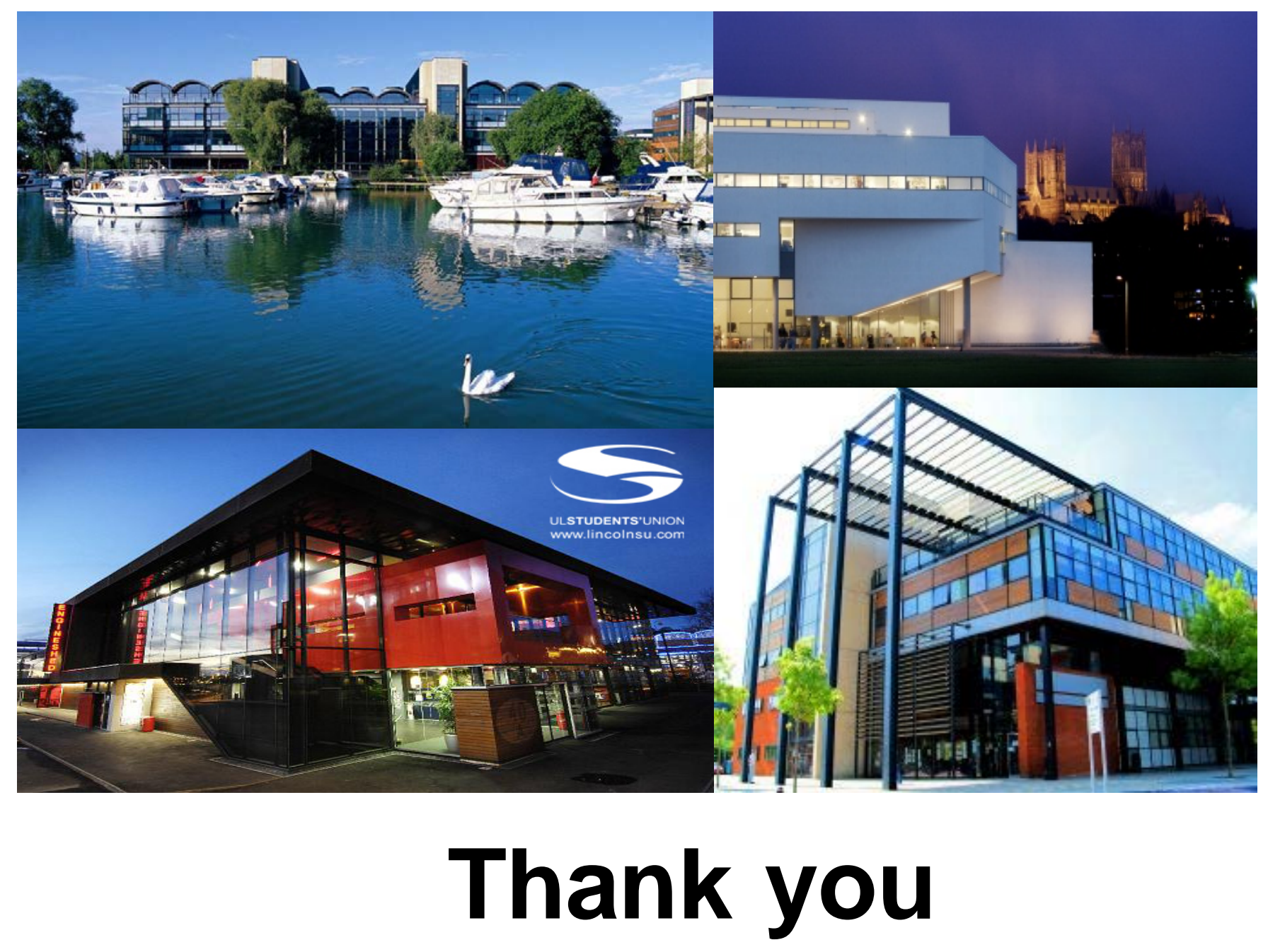

CaHRU@lincoln.ac.uk 